\title{
Hot spots and single nucleotide polymorphisms on the interaction interface of RAD51 and p53 complex
}

\author{
Kleber Santiago Freitas e Silva* \\ Biological Sciences Institute, Federal University of Goiás, Brazil
}

\begin{abstract}
Cancer statistics have increased worldwide over the years. The molecular basis for the onset of a cancer cell lies on genetic predisposition, endogenous compounds produced by cell metabolism, certain types of infection and environmental factors. Accumulated genetic alterations, such as mutations and polymorphisms, lead to a genome instability and consequently makes a regular cell into a cancer cell. Bioinformatics approaches, such as, systems biology and the investigation of hot spots on the interface of protein-protein interactions (PPIs), have helped the identification and design of small bioactive molecules to modulate PPIs and inactivate tumorous cells. Identifying polymorphic hot spot residues within protein domains or within interface of PPIs makes possible to reveal biochemical features and organization of pathways related to the onset of cancer that would confer survivability to cancer cells due to entropic advantage. RAD51 and p53 are strong candidate genes that influence susceptibility to cancer. Both proteins contain functional domains and interact with several other proteins, including tumor suppressors, oncogenes and DNA repairing proteins. Cancer shows a very complex genetic, molecular and biochemical signature. Biomedical research is driven towards a wider comprehension of the functional importance of polymorphisms and their association with human diseases. Here, we analyzed the interface of interaction between RAD 51 and $\mathrm{p} 53$ and identified hot spots that could be of importance for the conformational structure of those proteins, their function and pattern of interaction with their partners. We have also shown that some of the hot spot amino acid residues are polymorphic, which could disrupt the interaction between p53 and RAD5, leading to a higher susceptibility to cancer. Future studies should be conducted in order to design small molecules that could modulate the interaction between RAD 51 and p53 and guarantee proper homologous recombination and maintenance of genomic stability.
\end{abstract}

\section{Introduction}

Cancer statistics have increased worldwide over the years. The increasing number of populations, aging, risk factors such as smoking, obesity and eating habits, sedentarism and urbanization account for the high number of patients and deaths caused by cancer [1,2]. It was estimated that more than 14 million new cases of cancer and more than 8 million deaths worldwide took place in 2012 [3]. Lung cancer is the leading cause of deaths in males while breast cancer is responsible for most of the cases of deaths by cancer in females [4,5]. Recently, large amounts of genetic and molecular information about cancer have been discovered [6-11]. The molecular basis for the onset of a cancer cell lies on genetic predisposition, endogenous compounds produced by cell metabolism, certain types of infection and environmental factors [12-15]. Accumulated genetic alterations, such as mutations and polymorphisms, lead to a genome instability and consequently makes a regular cell into a cancer cell [16].

Experimental approaches, such as high-throughput techniques, have contributed to increase our knowledge on the disease $[17,18]$. Bioinformatics have aroused as a useful tool to analyze biochemically the cancer microenvironment and have contributed to increase our knowledge as well, besides offering new therapeutic strategies in order to control and avoid cancer progression [19]. Bioinformatics approaches, such as, systems biology and the investigation of hot spots on the interface of protein-protein interactions (PPIs), have helped the identification and design of small bioactive molecules to modulate PPIs and inactivate tumorous cells [20-22]. Hot spot residues are generally conserved among proteins with similar function or protein families carrying certain domains. Thus, mutations on those conserved hot spots amino acid residues may disrupt the best conformational state of a protein, its function and its capability of binding to protein partners, leading to the development of diseases [23]. Identifying polymorphic hot spot residues within protein domains or within interface of PPIs makes possible to reveal biochemical features and organization of pathways related to the onset of cancer that would confer survivability to cancer cells due to entropic advantage [24]. Knowledge that would drive the therapeutics of the disease and a better prognostic.

The genotype-phenotype relationship is the basis for the molecular and genetic characterization of cancer risk along with the identification of endogenous and environmental factors $[25,26]$. Single nucleotide polymorphisms have been pointed as one of the most important genetic factors that alter cell metabolism through anomalies in expression of important cancer-related proteins such as RAD51 and p53 [2732]. A polymorphism is defined by a variation in the DNA sequence that occurs in a population with a frequency of at least $1 \%$ [33]. Lowpenetrance genetic polymorphisms is the reason certain patients are more susceptible than others to environmental carcinogens, xenobiotics and drug resistance $[34,35]$.

RAD51 and p53 are strong candidate genes that influence susceptibility to cancer. Both proteins contain functional domains

${ }^{\star}$ Correspondence to: Kleber Santiago Freitas e Silva, Alameda Palmeiras Chácaras Califórnia, Goiânia - GO, 74710-310, Brazil, Tel: 5562 32820744; Email: smallbinho@hotmail.com

Key words: RAD51, p53, Cancer, Bioinformatics, homologous recombination

Received: September 03, 2018; Accepted: September 19, 2018; Published: September 23, 2018 
and interact with several other proteins, including tumor suppressors, oncogenes and DNA repairing proteins. RAD51 has several functions, including an activity in homologous recombination of DNA that underwent double strand break (DSB). Its function is accomplished by the formation of a helical nucleoprotein filament around the DNA and this RAD51-DNA complex is stabilized by PPIs in order to maintain genomic integrity [36]. The $\mathrm{p} 53$ protein is a multifunctional macromolecule that plays important roles in apoptosis, genomic stability, inhibition of angiogenesis and regulation of the cell cycle progression [37,38]. It is known as the guardian of the genome due to its importance regulating tumorigenesis and influencing the onset and progression of several types of cancer [39-43]. Polymorphisms present in RAD51 and p53 amino acid residues may alter PPIs patterns and increase susceptibility to diseases.

Cancer shows a very complex genetic, molecular and biochemical signature. Biomedical research is driven towards a more wide comprehension of the functional importance of polymorphisms and their association with human diseases. Here, we propose an in silico model of interaction between RAD51 and p53, analyze the interface of interaction and identify conserved hot spots and polymorphic amino acid residues as a way to modulate such interaction.

\section{Materials and methods}

The RAD51 3-D structure used in the analysis is available in the PDB (protein databank; https://www.rcsb.org/). The p53 tertiary structure was modeled by homology in the I-TASSER server. The i-TASSER modeling is based on templates of homologous proteins with experimental structure already resolved and available in the PDB [44]. The KBDOCK server was used to identify protein domains and interaction between protein domains [45]. The protein-protein docking was performed by the ClusPro server [46]. Briefly, the proteinprotein docking is based on thermodynamics in order to find the conformational structure at the minimum of Gibbs free energy.

The free version of PyMol (https://pymol.org) was used for the visualization of the interface of interaction, the visualization of hot spots and the polymorphic residues. Hot spots residues were identified by the KFC2 server. KFC2 assesses the biochemical environment around each residue in the complex structure and compares with known hot spots already determined experimentally. The prediction is based on two main parameters, the first one related to a conformation specificity (K-FADE) and the second to biochemical features (K-CON) $[47,48]$. Finally, the polymorphic residues were identified through the dbSNP (data base of single nucleotide polymorphism; https://www. ncbi.nlm.nih.gov/SNP).

\section{Results and Discussion}

\section{RAD51 and p53 conformational structure and their functions}

RAD51 builds up helical filaments around DNA that are active during homologous recombination [49,50]. The dynamic structure of RAD51 promotes the formation of presynaptic filament encircling single-stranded DNA and the specific pairing with homologous double-stranded DNA filament [51,52]. RAD51 naturally undergoes oligomerization, up to 7 identical chains, in order to form the helical structures with slightly distinct symmetry among species [53]. RAD51 also forms a very flexible amino terminal chain implicated in DNA binding [54]. The guardian of the genome interacts with a large variety of partners and take part in several cellular signal pathway in order to maintain the integrity of the genome [55]. The protein folds into a homotetramer structure comprising intrinsically disordered domains related to oligomerization and DNA binding region. Disorder regions are the reason why p53 has a great number of protein partners and is related to many functions in cells [56]. Details on its conformation has brought information regarding how disruption of the p53 structure by mutations could lead to cancer onset and development $[57,58]$. Common polymorphisms have been identified for both RAD51 and $\mathrm{p} 53$, and although it is unlikely that an SNP would change significantly the overall tertiary structure of a given protein, it could affect the freebinding energy of interaction with other proteins and increase the susceptibility of carriers to develop diseases. (Figure 1A and 1B)

\section{RAD51 and p53 interface of interaction}

The protein p53 interact with proteins related to DNA recombination and DNA repair in order to disrupt certain random phenomena, such as aberrant recombination, gene duplication, translocation, inversion and deletion, that would lead to disease $[59,60]$. Defining the binding regions and biochemical properties of p53 and RAD51 interaction is convenient in order to propose functional consequences of the interaction [61]. Figure $2 \mathrm{~A}$ and $2 \mathrm{~B}$ show the interface interaction between RAD51 and p53. The region is rather large and features the absence of empty spaces or active binding pockets that are normally present at active sites of proteins. The significance of $\mathrm{p} 53$ and RAD51 conformations for their interaction lies on certain facts like posttranslational modifications, oligomerization and regulation of PPI by basic residues of amino acid located on the C-terminal portion of the protein $[59,61]$.

\section{Prediction of hot spots on the interface of interaction between RAD51 and p53}

Hot spots are special amino acid residues that account for a considerable portion of the binding free-energy between interacting proteins $[62,63]$. These special residues maintain the stability of PPIs and therefore they are related to specific functions performed by the protein or complex of proteins $[64,65]$. Hot spots are experimentally determined by mutagenesis approaches. Online servers, such as KFC2, rely on experimental data and predict hot spots through in silico approaches.

We found 11 hot spots on the interface of interaction between RAD51 and p53. Among those, 6 were located on RAD1 structure and 4 were located on $\mathrm{p} 53$ structure (Table 1). These amino acid residues are highly conserved among species that code for these proteins. The hot spot prediction and the determination of the interface of interaction between RAD51 and p53 in the present approach were performed using different servers, KFC2 and ClusPro, respectively. Even so, as one would expect, the hot spots were predicted right on the region that is considered the interface of interaction with the lowed free-energy (Figure 3A,3B).

\section{Polymorphic residues that may affect the interaction between RAD51 and p53}

Genetic variation within a given population may increase the susceptibility to diseases. If the mentioned variation occur within the interface of interaction, or more specifically in hot spots amino acid residues the function of proteins, their conformational structures and pattern of PPIs may be changed and lead to the onset of diseases. We found three polymorphic hot spots residues within the RAD51 interface of interaction with p53 and three polymorphic hot spots within the p53 interface of interaction with RAD51 (Figure 4A,4B). 
For the RAD51 protein, the hot spot residues Arg27 and Glu50 can be changed into Trp and Cys respectively and and Arg215 comprise a synonymous mutation. For the 533 protein, the hot spot residues Asn 29, Arg 290 and Glu 286 can be polymorphically replaced by Lys, Cys and Gly, respectively. We also found other polymorphic residues on the interface of interaction encircling the predicted hot spot residues, which could affect structure, function and PPIs to a lesser extent.

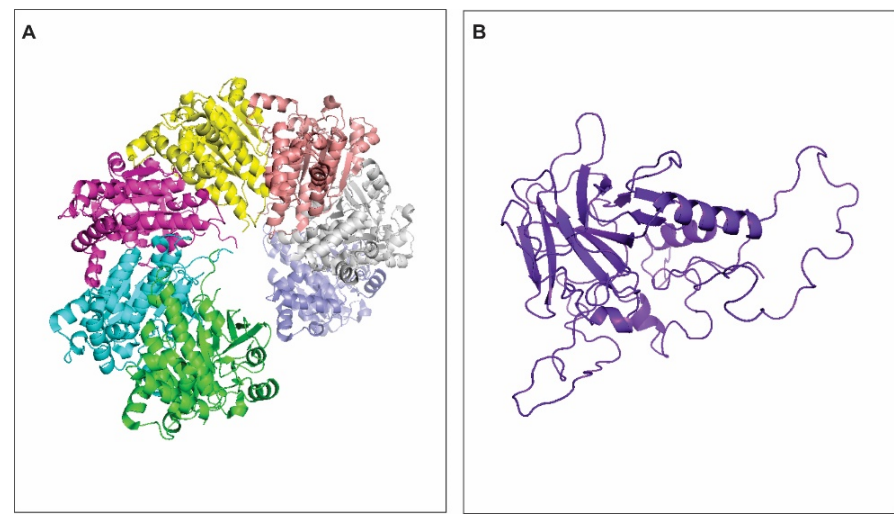

Figure 1. Tertiary structure of RAD51 (A) and p53 (B). A - RAD51 structure comprises seven identical chains (each one represented in a different color). B - p53 monomer. The p53 protein folds into a homotetramer and its oligomerization is important for the protein function

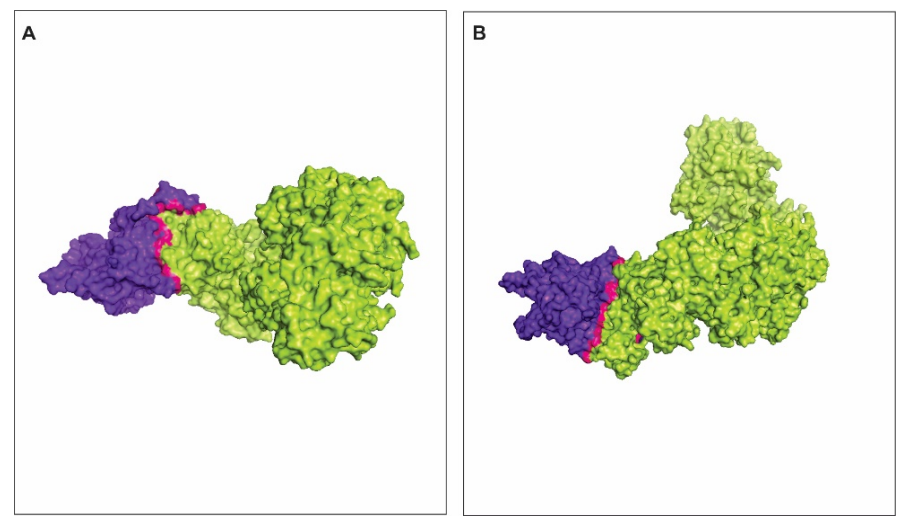

Figure 2. Interface of interaction between RAD51 and $\mathrm{p} 53$. The interface of interaction is represented in pink. A and B shows two different views of the interaction between RAD51 (green) and p53 (blue). The model represent the lowest energy of interaction and was calculated by ClusPro [46]

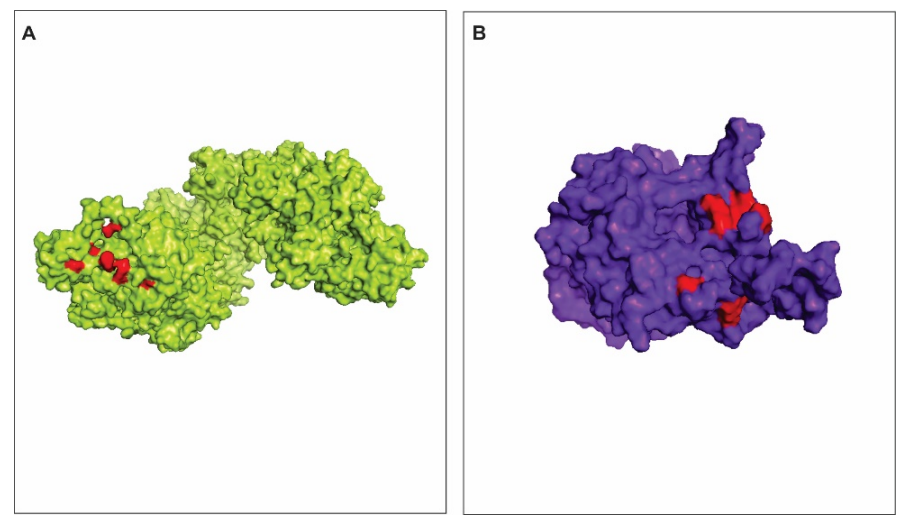

Figure 3. Hot spots prediction on the interface of interaction between RAD51 and p53. A - Hot spots (red residues) in the RAD51 structure (green) on the region of interaction with p53. B - Hot spots (red residues) in the p53 structure (blue) on the region of interaction with RAD51

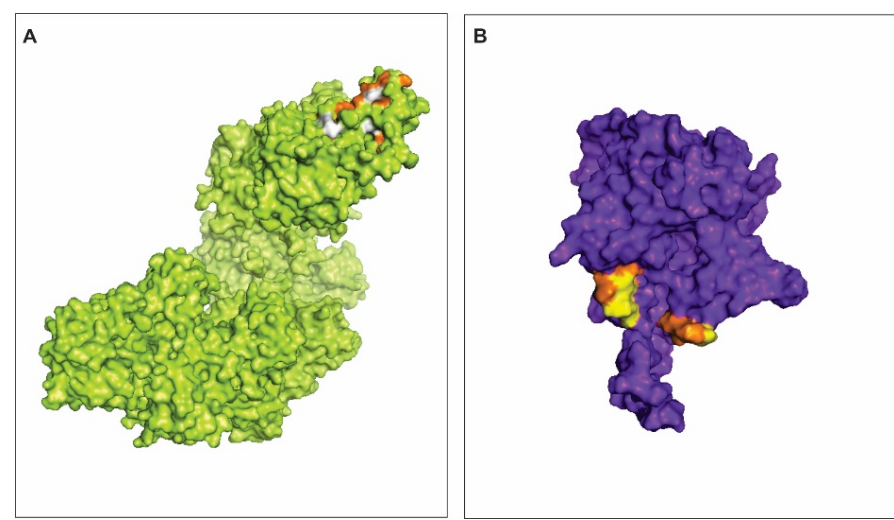

Figure 4. Polymorphic residues on the interaction interface between Rad51 and p53. A -The RAD51 structure. The orange residues represent polymorphic amino acids that were classified as hot spots residues by KFC2. The white residues represent polymorphic amino acid encircling hot spots. B - The p 53 structure. Orange residues are polymorphic amino acids classified as hot spots residues by KFC2. The yellow residues represent polymorphic amino acid around hot spots areas

Table 1. Cluster of hot spot residues on the interface of interaction between RAD51 and p53

\begin{tabular}{|c|c|c|c|c|}
\hline Chain & Residue & KFC2-A $^{*}$ & KFC2-B** $^{* *}$ & Protein \\
\hline A & PHE 20 & 1.29 & 0.02 & RAD51 \\
\hline A & ARG $27^{\S}$ & 1.71 & 0.29 & RAD51 \\
\hline A & GLU $50^{\S}$ & 1.08 & 0.01 & RAD51 \\
\hline A & ARG 95 & 0.89 & 0.18 & RAD51 \\
\hline A & GLN 145 & 0.97 & 0.03 & RAD51 \\
\hline A & ARG 215 & 1.25 & 0.20 & RAD51 \\
\hline a & TRP 23 & 0.44 & 0.16 & RAD51 \\
\hline a & LYS 24 & 1.65 & 0.28 & p53 \\
\hline a & ASN 29 & 1.91 & 0.11 & p53 \\
\hline a & GLU 286 & 0.84 & 0.11 & p53 \\
\hline a & ARG 290 & 1.89 & 0.33 & p53 \\
\hline
\end{tabular}

* Hot spot model based on shape specificity features.

** Hot spot model based on biochemical features such as intermolecular hydrogen bonds.

It has been show that certain variations alter the pattern of interaction between RAD51 and p53 [59,61]. Moreover, such polymorphisms on 553 may alter the pattern of interaction presented by RAD51 and diminish or even inhibit its functions by inhibiting its ability to bind to other protein partners [59]. The transcriptional factor function exerted by $\mathrm{p} 53$ and its DNA binding domain makes this protein highly sensitive to mutation at this region, altering not only its ability to bind to DNA but phosphorylation patterns and interaction with its partners [66-68]. It has also been shown that missense polymorphisms in p53 amino acid residues within conserved domains reduce the efficiency of its interaction with RAD51 [59], increasing the risk of indiscriminate homologous recombination, therefore, cancer.

\section{Concluding remarks}

Bioinformatics have provided important tools for our understanding of complex multiprotein structures. The possibility of lidentifying biochemical properties of protein interaction regions has led scientists to develop new ways of diagnose and treatment of diseases such as cancer. Here, we analyzed the interface of interaction between RAD51 and p53 and identified hot spots that could be of importance for the conformational structure of those proteins, their function and pattern of interaction with their partners. We have also shown that some of the hot spot amino acid residues are polymorphic, which could disrupt the interaction between p53 and RAD5, leading to a higher susceptibility to cancer. Future studies should be conducted in order 
to design small molecules that could modulate the interaction between RAD51 and p53 and guarantee proper homologous recombination and maintenance of genomic stability.

\section{References}

1. Bray F, Møller B (2006) Predicting the future burden of cancer. Nat Rev Cancer 6: 63-74. [Crossref]

2. Siegel RL, Miller KD, Jemal A (2018) Cancer statistics. CA Cancer J Clin. janeiro de 68: 7-30.

3. Torre LA, Bray F, Siegel RL, Ferlay J, Lortet-Tieulent J, et al. (2015) Global cancer statistics, 2012. CA Cancer J Clin 65: 87-108. [Crossref]

4. Hamra GB, Guha N, Cohen A, Laden F, Raaschou-Nielsen O, et al. (2014) Outdoor particulate matter exposure and lung cancer: a systematic review and meta-analysis. Environ Health Perspect 122: 906-911. [Crossref]

5. Chlebowski RT, Manson JE, Anderson GL, Cauley JA, Aragaki AK, et al. (2013) Estrogen plus progestin and breast cancer incidence and mortality in the Women's Health Initiative Observational Study. J Natl Cancer Inst 105: 526-535. [Crossref]

6. Al-Sohaily S, Biankin A, Leong R, Kohonen-Corish M, Warusavitarne J (2012) Molecular pathways in colorectal cancer. J Gastroenterol Hepatol 27: 1423-1431. [Crossref]

7. Rojas V, Hirshfield KM, Ganesan S, Rodriguez-Rodriguez L (2016) Molecular Characterization of Epithelial Ovarian Cancer: Implications for Diagnosis and Treatment. Int J Mol Sci 17

8. Zardavas D, Piccart-Gebhart M1 (2015) Clinical Trials of Precision Medicine through Molecular Profiling: Focus on Breast Cancer. Am Soc Clin Oncol Educ Book . [Crossref]

9. Zhong J, Chen Y, Wang L-J (2016) Emerging molecular basis of hematogenous metastasis in gastric cancer. World J Gastroenterol 22: 2434-2440. [Crossref]

10. Rodriguez-Canales J, Parra-Cuentas E, Wistuba II (2016) Diagnosis and Molecular Classification of Lung Cancer. Cancer Treat Res 170: 25-46. [Crossref]

11. Ryan BM, Faupel-Badger JM (2016) The hallmarks of premalignant conditions: a molecular basis for cancer prevention. Semin Oncol 43: 22-35. [Crossref]

12. Nagy R, Ringel MD (2015) Genetic predisposition for nonmedullary thyroid cancer. Horm Cancer 6: 13-20. [Crossref]

13. Sabharwal SS, Schumacker PT (2014) Mitochondrial ROS in cancer: initiators, amplifiers or an Achilles' heel? Nat Rev Cancer 14: 709-721. [Crossref]

14. Oh JK, Weiderpass E (2014) Infection and cancer: global distribution and burden of diseases. Ann Glob Health 80: 384-392. [Crossref]

15. Lichtenstein P, Holm NV, Verkasalo PK, Iliadou A, Kaprio J, et al. (2000) Environmental and heritable factors in the causation of cancer--analyses of cohorts of twins from Sweden, Denmark, and Finland. N Engl J Med 343: 78-85. [Crossref]

16. Yang Y, Liu P, Guo F, Liu R, Yang Y, et al. (2014) Genetic G2548A polymorphism of leptin gene and risk of cancer: a meta-analysis of 6860 cases and 7956 controls. $J$ BUON 19: 1096-1104. [Crossref]

17. Staal FJT, van der Burg M, Wessels LFA, Barendregt BH, Baert MRM, et al. DNA microarrays for comparison of gene expression profiles between diagnosis and relapse in precursor-B acute lymphoblastic leukemia: choice of technique and purification influence the identification of potential diagnostic markers. Leukemia 17:1324-1332. [Crossref]

18. Centeno BA, Enkemann SA, Coppola D, Huntsman S, Bloom G, et al. (2005) Classification of human tumors using gene expression profiles obtained after microarray analysis of fine-needle aspiration biopsy samples. Cancer 105: 101-109. [Crossref]

19. He F, Ai B, Tian L (2018) Identification of genes and pathways in esophageal adenocarcinoma using bioinformatics analysis. Biomed Rep 9: 305-312. [Crossref]

20. Alameddine AK, Conlin F, Binnall B (2018) An Introduction to the Mathematical Modeling in the Study of Cancer Systems Biology. Cancer Inform 17:1176935118799754. [Crossref]

21. Santucci M, Vignudelli T, Ferrari S, Mor M, Scalvini L, et al. (2015) The Hippo Pathway and YAP/TAZ-TEAD Protein-Protein Interaction as Targets for Regenerative Medicine and Cancer Treatment. J Med Chem 58:4857-4873. [Crossref]

22. Couture F, Levesque C, Dumulon-Perreault V, Ait-Mohand S, D'Anjou F, et al. (2014) PACE4-based molecular targeting of prostate cancer using an engineered $64 \mathrm{Cu}$ radiolabeled peptide inhibitor. Neoplasia 16: 634-643. [Crossref]
23. Chothia C, Gough J, Vogel C, Teichmann SA (2003) Evolution of the protein repertoire. Science 300: 1701-1703. [Crossref]

24. Tseng C-Y, Tuszynski J (2015) Entropic analysis reveals a connection between the recurrence of cancer and chemotherapy. Saudi J Biol Sci 22: 674-678. [Crossref]

25. Cho D-Y, Przytycka TM (2013) Dissecting cancer heterogeneity with a probabilistic genotype-phenotype model. Nucleic Acids Res 41: 8011-8020. [Crossref]

26. Gerlee P, Kim E, Anderson ARA (2015) Bridging scales in cancer progression: Mapping genotype to phenotype using neural networks. Semin Cancer Biol 30: 30-41. [Crossref]

27. Howe R, Miron-Shatz T, Hanoch Y, Omer ZB, O'Donoghue C, et al. (2015) Personalized Medicine Through SNP Testing for Breast Cancer Risk: Clinical Implementation. J Genet Couns 24: 744-751. [Crossref]

28. Grin B, Loeb S, Roehl K, Cooper PR, Catalona WJ, et al. (2015) A rare 8q24 single nucleotide polymorphism (SNP) predisposes North American men to prostate cancer and possibly more aggressive disease. BJU Int 115: 101-105. [Crossref]

29. Santos E de M, Santos HB de P, de Matos FR, Machado RA, Coletta RD, et al. Clinicopathological significance of SNPs in RAD51 and XRCC3 in oral and oropharyngeal carcinomas. Oral Dis. [Crossref]

30. Chen F, Zhang H, Pu F (2016) Association between a functional variant in RAD51 gene's 3' untranslated region and its mRNA expression in lymphoblastoid cell lines. Springerplus 5: 1688. [Crossref]

31. Arfaoui A, Douik H, Kablouti G, Chaaben AB, Handiri N, et al. (2015) Role of p53 Codon72 SNP in breast cancer risk and anthracycline resistance. Anticancer Res 35: 1763-1769. [Crossref]

32. Su H-X, Zhou H-H, Wang M-Y, Cheng J, Zhang S-C, et al. (2014) Mutations of C-reactive protein (CRP) -286 SNP, APC and p53 in colorectal cancer: implication for a CRP-Wnt crosstalk. PLoS ONE 9: e102418.

33. Brookes AJ (1999) The essence of SNPs. Gene 234: 177-186. [Crossref]

34. Ambrosone CB, Freudenheim JL, Marshall JR, Graham S, Vena JE, et al. (1995) The association of polymorphic N-acetyltransferase (NAT2) with breast cancer risk. Ann N $Y$ Acad Sci 768: 250-252. [Crossref]

35. Smith G, Stanley LA, Sim E, Strange RC, Wolf CR (1995) Metabolic polymorphisms and cancer susceptibility. Cancer Surv 25: 27-65. [Crossref]

36. Galkin VE, Wu Y, Zhang X-P, Qian X, He Y, et al. (2006) The Rad51/RadA $\mathrm{N}$-terminal domain activates nucleoprotein filament ATPase activity. Structure 14 983-992. [Crossref]

37. Muller PA, Vousden KH2 (2014) Mutant p53 in cancer: new functions and therapeutic opportunities. Cancer Cell 25: 304-317. [Crossref]

38. Dong P, Ihira K, Hamada J, Watari H, Yamada T, et al. (2015) Reactivating p53 functions by suppressing its novel inhibitor iASPP: a potential therapeutic opportunity in p53 wild-type tumors. Oncotarget 6: 19968-19975. [Crossref]

39. Kaypee S, Sahadevan SA, Patil S, Ghosh P, Roy NS, et al. (2018) Mutant and Wild-Type Tumor Suppressor p53 Induces p300 Autoacetylation. iScience 4: 260-272. [Crossref]

40. Motadi LR, Lekganyane MM, Moela P (2018) RBBP6 expressional effects on cell proliferation and apoptosis in breast cancer cell lines with distinct p53 statuses. Cancer Manag Res 10: 3357-3369. [Crossref]

41. Mattioni M, Soddu S, Prodosmo A, Visca P, Conti S, et al. (2015) Prognostic role of serum p53 antibodies in lung cancer. BMC Cancer 15: 148. [Crossref]

42. Mishra A, Brat DJ, Verma M (2015) P53 tumor suppression network in cancer epigenetics. Methods Mol Biol 1238: 597-605. [Crossref]

43. Li X-L, Zhou J, Chen Z-R, Chng W-J (2015) P53 mutations in colorectal cancer molecular pathogenesis and pharmacological reactivation. World J Gastroenterol 21 : 84-93. [Crossref]

44. Zhang Y (2008) I-TASSER server for protein 3D structure prediction. BMC Bioinformatics 9: 40. [Crossref]

45. Ghoorah AW, Devignes MD, Smaïl-Tabbone M, Ritchie DW (2016) Classification and Exploration of 3D Protein Domain Interactions Using Kbdock. Methods Mol Biol 1415: 91-105. [Crossref]

46. Kozakov D, Hall DR, Xia B, et al. (2017) The ClusPro web server for protein-protein docking. Nat Protoc 12: 255-278. [Crossref]

47. Darnell SJ, Page D, Mitchell JC (2007) An automated decision-tree approach to predicting protein interaction hot spots. Proteins 68: 813-823. [Crossref] 
48. Darnell SJ, LeGault L, Mitchell JC (2008) KFC Server: interactive forecasting of protein interaction hot spots. Nucleic Acids Res 36: W265-W269. [Crossref]

49. Shinohara A, Ogawa H, Ogawa T (1992) Rad51 protein involved in repair and recombination in S. cerevisiae is a RecA-like protein. Cell 69: 457-470. [Crossref]

50. Aboussekhra A, Chanet R, Adjiri A, Fabre F (1992) Semidominant suppressors of Srs2 helicase mutations of Saccharomyces cerevisiae map in the RAD51 gene, whose sequence predicts a protein with similarities to procaryotic RecA proteins. Mol Cell Biol 12: 3224-3234. [Crossref]

51. Baumann P, Benson FE, West SC (1996) Human Rad51 protein promotes ATPdependent homologous pairing and strand transfer reactions in vitro. Cell 87: 757-766. [Crossref]

52. Sung P (1994) Catalysis of ATP-dependent homologous DNA pairing and strand exchange by yeast RAD51 protein. Science 265: 1241-1243. [Crossref]

53. Chen Z, Yang H, Pavletich NP (2008) Mechanism of homologous recombination from the RecA-ssDNA/dsDNA structures. Nature 453: 489-484. [Crossref]

54. Aihara H, Ito Y, Kurumizaka H, Yokoyama S, Shibata T (1999) The N-terminal domain of the human Rad51 protein binds DNA: structure and a DNA binding surface as revealed by NMR. J Mol Biol 290: 495-504. [Crossref]

55. Vousden KH, Prives C (2009) Blinded by the Light: The Growing Complexity of p53. Cell 137: 413-431. [Crossref]

56. Joerger AC, Fersht AR (2010) The Tumor Suppressor p53: From Structures to Drug Discovery. Cold Spring Harb Perspect Biol 2: a000919. [Crossref]

57. Herrero AB, Rojas EA, Misiewicz-Krzeminska I, Krzeminski P, Gutiérrez NC (2018) Molecular Mechanisms of p53 Deregulation in Cancer: An Overview in Multiple Myeloma. Int J Mol Sci 17. [Crossref]
58. Yue X, Zhao Y, Xu Y, Zheng M, Feng Z, et al. (2017) Mutant p53 in Cancer: Accumulation, Gain-of-Function, and Therapy. J Mol Biol 429: 1595-1606. [Crossref]

59. Buchhop S, Gibson MK, Wang XW, Wagner P, Stürzbecher HW, et al. (1997) Interaction of p53 with the human Rad51 protein. Nucleic Acids Res 25: 3868-3874. [Crossref]

60. Vogelstein B, Fearon ER, Hamilton SR, Kern SE, Preisinger AC, et al. (1988) Genetic alterations during colorectal-tumor development. $N$ Engl J Med 319: 525-532. [Crossref]

61. Stürzbecher HW, Donzelmann B, Henning W, Knippschild U, Buchhop S (1996) p53 is linked directly to homologous recombination processes via RAD51/RecA protein interaction. EMBO J. 15: 1992-2002. [Crossref]

62. Clackson T, Wells JA (1995) A hot spot of binding energy in a hormone-receptor interface. Science 267: 383-386. [Crossref]

63. Bogan AA, Thorn KS (1998) Anatomy of hot spots in protein interfaces. $J$ Mol Biol 280: 1-9. [Crossref]

64. Keskin O, Ma B, Nussinov R (2005) Hot regions in protein--protein interactions: the organization and contribution of structurally conserved hot spot residues. $J \mathrm{Mol} \mathrm{Biol}$ 345: 1281-1294. [Crossref]

65. Kortemme T, Baker D (2002) A simple physical model for binding energy hot spots in protein-protein complexes. Proc Natl Acad Sci USA 99: 14116-14121.

66. Harris CC (1993) p53: at the crossroads of molecular carcinogenesis and risk assessment. Science 262: 1980-1981. [Crossref]

67. Harris CC, Hollstein M (1993) Clinical implications of the p53 tumor-suppressor gene. N Engl J Med 329: 1318-1327. [Crossref]

68. Cho Y, Gorina S, Jeffrey PD, Pavletich NP (1994) Crystal structure of a p53 tumor suppressor-DNA complex: understanding tumorigenic mutations. Science 265: 346-355.

Copyright: $(2018$ Freitas e Silva KS. This is an open-access article distributed under the terms of the Creative Commons Attribution License, which permits unrestricted use, distribution, and reproduction in any medium, provided the original author and source are credited. 